\title{
PREVALENCE AND SEVERITY OF UNDIAGNOSED URINARY INCONTINENCE IN WOMEN
}

\author{
Lauren P. Wallner, M.P.H ${ }^{1,2}$, Sima Porten, M.D, M.P.H ${ }^{3}$, Richard T. Meenan, Ph. $\mathbf{D}^{4}$, Maureen \\ C. O'Keefe Rosetti, M.S ${ }^{4}$, Elizabeth A. Calhoun, Ph.D ${ }^{5}$, Aruna V. Sarma, Ph.D ${ }^{1,2}$, and J. \\ Quentin Clemens, M.D. 1 \\ ${ }^{1}$ University of Michigan, Department of Urology \\ ${ }^{2}$ University of Michigan, Department of Epidemiology \\ ${ }^{3}$ University of California at San Francisco, Department of Urology \\ ${ }^{4}$ Center for Health Research Kaiser Permanente Northwest Division \\ ${ }^{5}$ University of Illinois at Chicago School of Public Health, Department of Health Policy Administration
}

\begin{abstract}
Background-Urinary incontinence is a highly prevalent condition in aging women that results in significant morbidity. Less than half of women who suffer from urinary incontinence seek treatment resulting in a significant proportion of clinically relevant urinary incontinence remaining undiagnosed. Therefore, the purpose of this study was to quantify the prevalence of urinary incontinence in undiagnosed women in a managed care population.
\end{abstract}

Methods-136,457 women ages 25-80 enrolled in the Kaiser Permanente Northwest (KPNW) who were free of genitourinary diagnoses including urinary incontinence were included in this study. 875 of the 2,118 women who were mailed questionnaires ascertaining information on demographic and urinary incontinence characteristics completed the survey. A chart review of the 234 women who reported moderate to severe urinary incontinence was performed.

Results-The prevalence of undiagnosed urinary incontinence was 53\% in the preceding year, and $39 \%$ in the preceding week. The prevalence of undiagnosed stress, mixed and urge incontinence were found to be $18.7 \%, 12.0 \%$ and $6.8 \%$. Quality of life was found to significantly decrease with increasing urinary incontinence severity. $5 \%$ of the 234 chart reviewed women were found to have physician documented urinary incontinence.

Conclusions-These results suggest that a significant proportion of women in this managed care population are suffering from urinary incontinence that remains undiagnosed. Efforts should be made to encourage women and physicians to initiate conversations about urinary incontinence symptoms in order to decrease the unnecessary burden of this disease.

(C) 2009 Elsevier Inc. All rights reserved.

Corresponding Author: J. Quentin Clemens, M.D, M.S Department of Urology University of Michigan Medical Center 1500 East Medical Center Drive Taubman Center 3875 Ann Arbor, MI 48109-5330 phone: 734-232-4881 fax: 734-936-9127.

All seven authors on this manuscript have made a substantial contribution to writing the manuscript and had access to the data.

Publisher's Disclaimer: This is a PDF file of an unedited manuscript that has been accepted for publication. As a service to our customers we are providing this early version of the manuscript. The manuscript will undergo copyediting, typesetting, and review of the resulting proof before it is published in its final citable form. Please note that during the production process errors may be discovered which could affect the content, and all legal disclaimers that apply to the journal pertain. 


\section{Keywords}

Urinary incontinence; undiagnosed; urinary leakage

\section{INTRODUCTION}

Urinary incontinence, defined as the involuntary leakage of urine, affects $15-50 \%$ of women in the community, and results in annual direct costs of over $\$ 12$ billion in the United States ${ }^{1}$, ${ }^{2}$ While urinary incontinence is effectively treatable with medical, surgical and behavioral therapies, less than half of the women who suffer from urinary incontinence receive treatment. ${ }^{3}$ Barriers to incontinence care among women include the misconception that it is not a legitimate medical problem, the embarrassment surrounding the resulting symptoms, ${ }^{4}$ and the perception that it is a normal part of the aging process ${ }^{5}$ or the natural result of childbirth. ${ }^{6}$ These beliefs are compounded by a lack of knowledge about treatment options and fear of invasive medical interventions. ${ }^{3,7}$ As a result, women are less likely to initiate a conversation with their primary care physician about their urinary incontinence and thus, a significant portion of clinically relevant urinary incontinence among women goes undiagnosed and untreated in the United States.

In order to better characterize the burden of undiagnosed incontinence among US women, this study sought to determine the prevalence and severity of undiagnosed urinary incontinence in women aged 25-80, from the Kaiser Permanente Northwest (KPNW) managed care population.

\section{METHODS}

\section{Study Population}

The managed care population utilized for this study, Kaiser Permanente Northwest (KPNW), is a mostly Caucasian population of 436,000 enrollees representing the metropolitan Portland, Oregon area. KPNW has an $85 \%$ retention rate yearly and is unique in that EpicCare clinical information system, a comprehensive electronic medical record (EMR), was implemented beginning in 1998, which allows for population based research of physician diagnosed disorders. Women ages 25 to 80 who were members of KPNW for greater than 2 months, had at least 12 months of eligibility between January 1998 through May 2002, and who consented to be contacted for research purposes were included in this study. The initial inclusion criteria identified 136,457 women.

Women who had diagnoses of genitourinary cancer, neurologic disease, radiation cystitis or urethral diverticula in the EMR were excluded from the questionnaire mailing. Women with previously diagnosed urinary incontinence were also excluded. After applying these criteria, 115,117 women were identified as eligible for this study.

\section{Questionnaire}

A questionnaire ascertaining demographic and urinary incontinence information was mailed to random sample of 2,118 eligible women. Of these, 875 completed the questionnaire, yielding a $41 \%$ response rate. Questions regarding incontinence type and frequency of urinary leakage were included in the questionnaire. A comprehensive list of the incontinence specific questions is provided in Appendix 1.

Types of Incontinence-Urinary incontinence was defined in two ways: 1) leakage of any amount of urine during the past 12 months; and 2) leakage of any amount of urine during the 
past 7 days. In those with urinary incontinence in the past 7 days, the type of incontinence was categorized as stress, urge, or mixed. Stress incontinence was defined as accidentally leaking urine with physical activity such as coughing, sneezing, lifting or exercising. Urge incontinence was defined as accidental urine leakage that was associated with a strong urge to empty the bladder. Mixed incontinence was defined as having both stress and urge incontinence.

Severity of incontinence-In women who reported incontinence in the preceding week, the Sandvik Severity Index (SSI) was used to characterize the incontinence severity ${ }^{10}$. The SSI is a validated measurement of incontinence severity which has been shown to correlate with the objective measurement of incontinence using a 24 -hour pad test ${ }^{11}$. The SSI is comprised of an index score calculated by multiplying the frequency of incontinence by the amount of urine leaked, yielding four categories of severity: slight (1-2), moderate (3-6), severe (8-9) and very severe (12). Quality of life

Quality of life was assessed by asking survey participants the question, "If you had to spend the rest of your life with your urinary symptoms just the way they have been during the past month, how would you feel about that?' Response options include 'delighted', 'pleased', 'mostly satisfied', 'about equally satisfied and dissatisfied', 'mostly dissatisfied', 'unhappy', and 'terrible'. For analytic purposes, responses were categorized as Satisfied ('delighted', 'pleased', or 'mostly satisfied'), Mixed ('about equally satisfied and dissatisfied'), and Dissatisfied ('mostly dissatisfied', 'unhappy', and 'terrible').

Chart Review-Electronic medical records were reviewed in all women characterized by the SSI as having moderate or severe incontinence in the preceding week. Progress notes for the 12 months prior to the survey completion date (May-June 2000) were manually reviewed to determine whether there was documented evidence of urinary incontinence at the time of each contact with a healthcare provider. Number of contacts, type of contact (telephone vs. office visit), and provider specialty for each contact were recorded.

Statistical Analysis-Descriptive statistics were used to characterize the demographics and incontinence of the population Age-adjusted prevalence estimates were calculated for all types of incontinence and severity based on 5-year age distributions and standardized to the general KPNW female population. Associations with age were tested using Pearson chi-square test of associations and Cochran-Armitage tests for trend. To better quantify the magnitude of the relationship between severity and quality of life, odds ratios were estimated. An alpha level of 0.05 was used to determine statistical significance. All analyses were performed using SPSS (Version 14.0, SPSS Inc, Chicago, IL).

\section{RESULTS}

Among the 875 participants in this study, 461 (52.6\%) reported having urinary incontinence in the past 12 months, and 340 (38.9\%) reported having urinary incontinence in the past 7 days. The age-adjusted prevalence of undiagnosed urinary incontinence was $51 \%$ in the past 12 months, and $38 \%$ in the past 7 days. The age-adjusted rates of stress urinary incontinence, urge urinary incontinence and mixed urinary incontinence were $18.7 \%, 6.8 \%$ and $12.0 \%$, respectively. While the rates of urge urinary incontinence and mixed urinary incontinence were found to significantly increase with age (p-value trend: $<\mathbf{0 . 0 0 1 , 0 . 0 0 3 )}$, stress urinary incontinence was not found to be significantly associated with age in this cohort (p-value: (0.056). (TABLE 1)

The majority of women reported moderate (53.6\%) or slight urinary incontinence (34.5\%) symptoms as classified by their SSI score. (TABLE 2) The median number of any type of weekly incontinence episodes was 1 (range 1-35). (TABLE 2). The amount of leakage per 
incontinence episode tended to be small, with $63 \%$ of women reporting that they leak only "drops". The majority of women (68\%) reported using sanitary napkins or pads at least occasionally, and $46 \%$ reported occasionally having wet clothing as a result of their urinary leakage. (TABLE 2)

The severity of incontinence by age group and urinary incontinence type is displayed in Table 3. Within each of the three types of incontinence, no statistically significant association was seen between age and reported severity, with the majority of women across all age groups and all urinary incontinence types reporting either moderate or slight degree of symptoms. (TABLE 3)

Incontinence severity was found to be significantly associated with quality of life, with women of all three types of urinary incontinence reporting lower quality of life as urinary incontinence severity increased. (p-values <0.05) (FIGURE 1) None of the women reporting very severe urge or mixed urinary incontinence also reported being satisfied with her quality of life. The associations between increasing severity and decreasing quality of life for all three subtypes of urinary incontinence were found to be moderately strong in magnitude. (ORs: 2.5-8.6) (FIGURE 1)

A total of 234 women had moderate or severe incontinence based on the SSI. The median age of this group was 54 years (range 25-80), and $53(22.6 \%$ ) were 65 years or older. $43 \%$ of these women reported stress urinary incontinence, $32 \%$ reported urge urinary incontinence and $24 \%$ had mixed urinary incontinence. (TABLE 4) Review of the medical records of these patients was performed. For the 12 months prior to the questionnaire completion date, the median number of office visits was 4 (range 0-19), and the median number of telephone contacts was 2 (range $0-21$ ) (Table 4). Only $11(4.7 \%)$ of these women had urinary incontinence symptoms documented in the medical record.

\section{DISCUSSION}

In this managed-care population of women aged $25-80$, the prevalence of undiagnosed urinary incontinence was 53\% in the preceding year, and 39\% in the preceding week. Of these women, greater than $65 \%$ reported moderate to severe incontinence severity. While barriers in care have been suggested to result in a proportion of cases of urinary incontinence going undiagnosed in women, the magnitude of this problem is not well characterized. To date the majority of research estimates the prevalence of urinary incontinence based on self-report in a community setting and it is not well established whether or not these cases are physician diagnosed. Previous studies have estimated the prevalence of urinary incontinence in women to range anywhere from $18 \%$ to $69 \% .{ }^{8-11}$ The overall prevalence of incontinence tends to increase in young adulthood, with a steady increase seen among elderly women. ${ }^{12}$ Our results support this trend, in that with increasing age, the prevalence of undiagnosed urinary incontinence significantly increases. Stress incontinence is the primary type of urinary incontinence reported among younger women, with approximately $50 \%$ of urinary incontinence being stress. ${ }^{13}$ Urge incontinence becomes more prevalent with age, with urge and mixed incontinence explaining the majority of urinary incontinence in older women. ${ }^{14} \mathrm{In}$ this study, the rates of undiagnosed stress, mixed and urge incontinence were found to be $18.7 \%, 12.0 \%$ and $6.8 \%$, respectively.

Our results suggest that undiagnosed incontinence is a nontrivial problem, with substantial impact on quality of life. The majority of women in this sample reported moderate severity of symptoms regardless of subtype. $70 \%$ of women with undiagnosed incontinence had symptoms for greater than one year, and approximately $50 \%$ reported wet clothes due to urine leakage. 
These results suggest that undiagnosed incontinence is equally common as diagnosed incontinence in women, and that the incontinence tends to be frequent, lasting, and bothersome.

The chart reviews of women with moderate to severe incontinence symptoms revealed that the vast majority of these women do not simply lack billing codes for urinary incontinence. Rather, the incontinence is apparently unrecognized by caretakers. The majority of the women (74\%) had at least one health maintenance examination in the preceding year. Therefore, it appears that physician-patient communication about urinary incontinence is poor. One might expect the burden of undiagnosed incontinence to be more severe in non-managed care populations, where access to care is more limited. Although the present study did not address the reasons for this poor communication, previous studies have shown that many factors are involved such as patient embarrassment about the condition, presence of more acute or severe medical conditions which take precedence during the office visit, and limited understanding of the condition by patients and physicians. $3,7,15$

While this study is one of the first to quantify the magnitude of undiagnosed urinary incontinence in women, there are limitations to consider. The questionnaire response rate of $41 \%$ was suboptimal, and it is possible that this influenced the results. Although the ICD-9 diagnoses of non-respondents were found to only slightly differ from the respondents, women with incontinence symptoms may be more likely to respond than those without symptoms resulting in an overestimate of the urinary incontinence prevalence in this population. However, it is somewhat reassuring that our incontinence prevalence estimates are similar to those from prior questionnaire studies with higher response rates. ${ }^{13,16,17}$ Second, while the question ascertaining urinary incontinence in the past 12 months may overestimate the prevalence of urinary incontinence in the past year, the majority of our results are focused on the prevalence of urinary incontinence in the past 7 days, thus limiting the effects of this bias. Finally, the chart reviews were limited to the year preceding questionnaire administration, and therefore discussions about incontinence symptoms that occurred prior to this interval would be unrecognized. Finally, the majority of study participants were Caucasian and of similar demographics, thus limiting the generalizability of our results to other ethnicities and demographic groups.

In conclusion, among women aged $25-80$ in a managed care population, the prevalence of undiagnosed urinary incontinence was found to be 53\% in the past year and 39\% in the past week, with $65 \%$ reporting moderate to severe symptoms. These results suggest that a significant proportion of women are suffering from clinically relevant urinary incontinence that remains undiagnosed. Because urinary incontinence is largely treatable in women, efforts need to be made to encourage women as well as their physicians to identify and discuss their

incontinence symptoms in order to decrease the unnecessary burden of this disease.

\section{Acknowledgments}

J. Quentin Clemens acknowledges that he had full access to all of the data in the study and takes responsibility for the integrity of the data and the accuracy of the data analysis

\section{Appendix 1}

Incontinence Questionnaire Items

Many people complain that they leak urine (wet themselves) or have accidents. In the past Yes/No

12 months, have you leaked even a small amount of urine?

If "Yes" about how long have you had urine leakage?

Less than 3 months

3 to less than 6 months

6 to less than 12 months

1 year to less than 5 years 


\section{5 years or more}

During the past 7 days, how many times did you accidentally leak urine:

- When you were performing some physical activity such as coughing, sneezing, lifting, or exercise?

- When you had the strong feeling that you needed to empty your bladder but couldn't get to the toilet fast enough?

- Without any particular physical activity or warning?

\begin{tabular}{ll}
\hline When you leak urine, about how much is it? & Drops or a little \\
Would you say: & Small splashes \\
& Or more
\end{tabular}

How often do you wear pads or sanitary napkins, or change your underwear due to urine Never loss? Would you say:

Occasionally

Almost Always

Always

Sometimes people have wet clothes due to urine loss. By wet, we mean wet through their Never

underwear to the next layer of clothing (or sheets, couch, etc). How often do you have wet

clothes due to urine loss? Would you say:

$$
\begin{aligned}
& \text { Occasionally } \\
& \text { Almost Always } \\
& \text { Always }
\end{aligned}
$$

\section{Clinical Significance}

- Undiagnosed urinary incontinence was common in this female managed care population.

- The incontinence occurred at least weekly in the majority of women, and caused a significant detrimental impact on quality of life.

- Effective therapies exist for urinary incontinence. Continued efforts are needed to encourage women and their physicians to identify and discuss their incontinence symptoms in order to decrease the unnecessary burden of this disease.

\section{Reference List}

1. Wilson L, Brown JS, Shin GP, Luc KO, Subak LL. Annual direct cost of urinary incontinence. Obstet Gynecol September;2001 98(3):398-406. [PubMed: 11530119]

2. Nygaard, ITDCE. Urologic Diseases in America. US Department of Health and Human Services, Public Health Service, National Institutes of Health, National Institute of Diabetes and Digestive and Kidney Diseases. US Government Printing Office; Washington, DC: 2007.

3. Dugan E, Roberts CP, Cohen SJ, et al. Why older community-dwelling adults do not discuss urinary incontinence with their primary care physicians. J Am Geriatr Soc April;2001 49(4):462-5. [PubMed: 11347792]

4. Shaw C, Tansey R, Jackson C, Hyde C, Allan R. Barriers to help seeking in people with urinary symptoms. Fam Pract February;2001 18(1):48-52. [PubMed: 11145628]

5. Kinchen KS, Burgio K, Diokno AC, Fultz NH, Bump R, Obenchain R. Factors associated with women's decisions to seek treatment for urinary incontinence. J Womens Health (Larchmt) September;2003 12(7):687-98. [PubMed: 14583109]

6. Goldstein M, Hawthorne ME, Engeberg S, McDowell BJ, Burgio KL. Urinary incontinence. Why people do not seek help. J Gerontol Nurs April;1992 18(4):15-20. [PubMed: 1569296]

7. Norton PA, MacDonald LD, Sedgwick PM, Stanton SL. Distress and delay associated with urinary incontinence, frequency, and urgency in women. BMJ November 5;1988 297(6657):1187-9. [PubMed: 3144344]

8. Moller LA, Lose G, Jorgensen T. The prevalence and bothersomeness of lower urinary tract symptoms in women 40-60 years of age. Acta Obstet Gynecol Scand April;2000 79(4):298-305. [PubMed: 10746846] 
9. Sampselle CM, Harlow SD, Skurnick J, Brubaker L, Bondarenko I. Urinary incontinence predictors and life impact in ethnically diverse perimenopausal women. Obstet Gynecol December;2002 100(6): 1230-8. [PubMed: 12468167]

10. Anger JT, Saigal CS, Stothers L, Thom DH, Rodriguez LV, Litwin MS. The prevalence of urinary incontinence among community dwelling men: results from the National Health and Nutrition Examination survey. J Urol November;2006 176(5):2103-8. [PubMed: 17070268]

11. Swithinbank LV, Donovan JL, du Heaume JC, et al. Urinary symptoms and incontinence in women: relationships between occurrence, age, and perceived impact. Br J Gen Pract November;1999 49 (448):897-900. [PubMed: 10818656]

12. Hannestad YS, Rortveit G, Sandvik H, Hunskaar S. A community-based epidemiological survey of female urinary incontinence: the Norwegian EPINCONT study. Epidemiology of Incontinence in the County of Nord-Trondelag. J Clin Epidemiol November;2000 53(11):1150-7. [PubMed: 11106889]

13. Thom D. Variation in estimates of urinary incontinence prevalence in the community: effects of differences in definition, population characteristics, and study type. J Am Geriatr Soc April;1998 46 (4):473-80. [PubMed: 9560071]

14. Holroyd-Leduc JM, Tannenbaum C, Thorpe KE, Straus SE. What type of urinary incontinence does this woman have? JAMA March 26;2008 299(12):1446-56. [PubMed: 18364487]

15. Horrocks S, Somerset M, Stoddart H, Peters TJ. What prevents older people from seeking treatment for urinary incontinence? A qualitative exploration of barriers to the use of community continence services. Fam Pract December;2004 21(6):689-96. [PubMed: 15528285]

16. Swanson JG, Kaczorowski J, Skelly J, Finkelstein M. Urinary incontinence: common problem among women over 45. Can Fam Physician January 1;2005 51(1):84-5. [PubMed: 16926957]

17. THOM DH, NYGAARD IE, CALHOUN EA. UROLOGIC DISEASES IN AMERICA PROJECT: URINARY INCONTINENCE IN WOMEN--NATIONAL TRENDS IN HOSPITALIZATIONS, OFFICE VISITS, TREATMENT AND ECONOMIC IMPACT. The Journal of Urology April;2005 173(4):1295-301. [PubMed: 15758785] 
A) Stress Urinary Incontinence (chi-square 41.49, p value $<0.001$ )

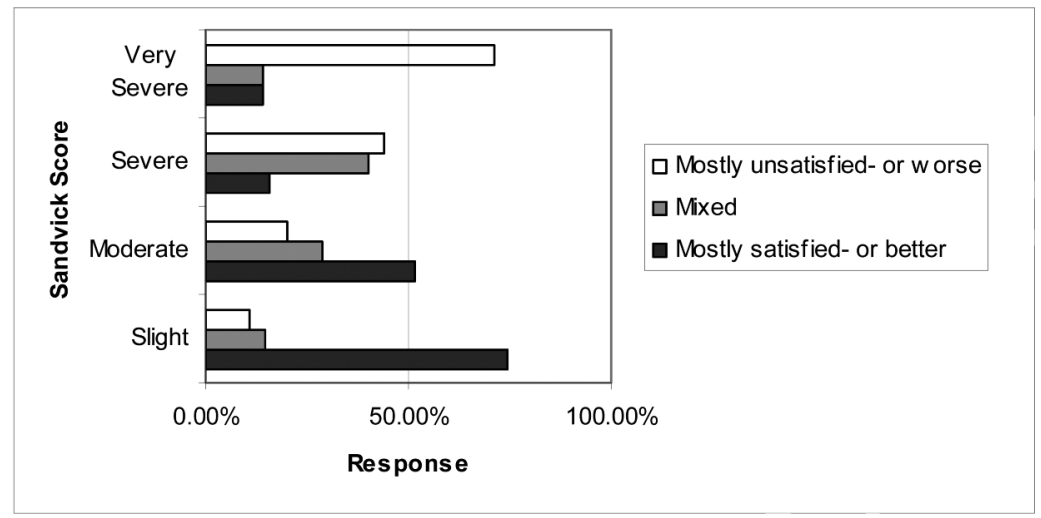

B) Urge Urinary Incontinence (chi-square 20.35, p value $<0.01$ )

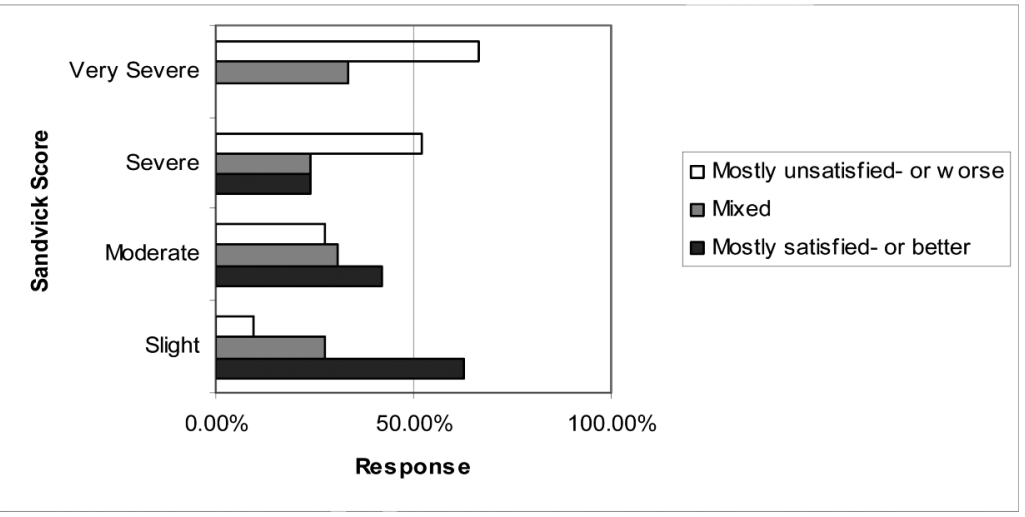

C) Mixed Urinary Incontinence (chi-square 13.59, p value <0.05)

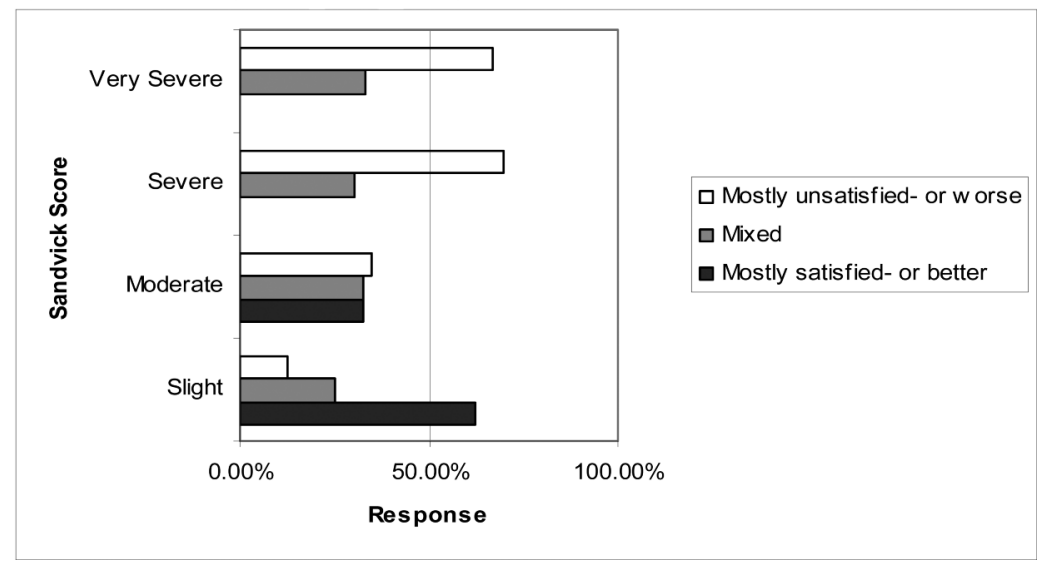

Figure 1.

Incontinence severity and quality of life in undiagnosed women 


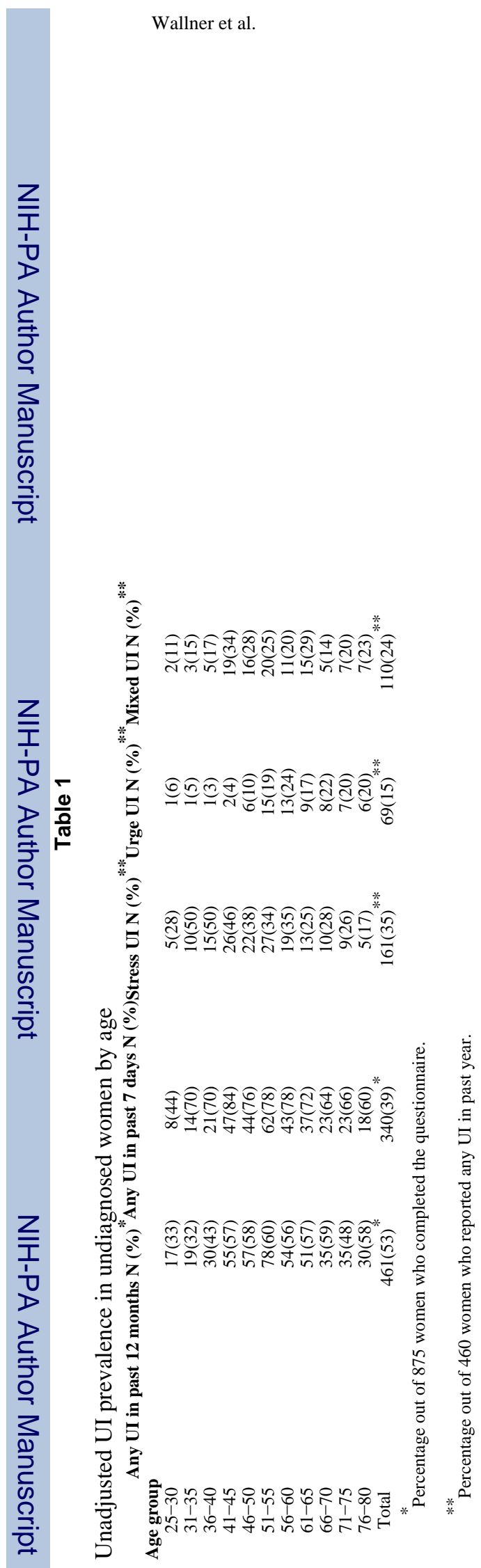

Am J Med. Author manuscript; available in PMC 2010 November 1. 


\section{Table 2}

Characteristics of UI in undiagnosed women reporting any UI in the past 7 days $(n=470)$

UI Characteristics

Episodes of urine leakage per weekMedian (range)

Stress

Urge

2(0-35)

Mixed

$1(0-25)$

Amount of urine leakage

2(0-30)

Drops

Splashes

$\mathrm{N}(\%)$

$292(63)$

133 (29)

More

$24(5)$

Sandvik Severity

Slight

$130(34.3)$

204(53.8)

Moderate

Severe

$37(9.8)$

Very severe

$8(2.1)$

Duration of urine leakage

$<12$ months

134 (30)

-5 years

$200(43)$

$>5$ years

118 (26)

Use of Sanitary Napkins/ Pads

Never

147(32)

223(48)

$\begin{array}{lc}\text { Almost Always } & 32(7) \\ \text { Always } & 57(12)\end{array}$

Always

Wet Clothes due to urine leakage

Never

227(49)

Occasionally

Almost Always

212(46)

$13(3)$

Always

2(0.4) 


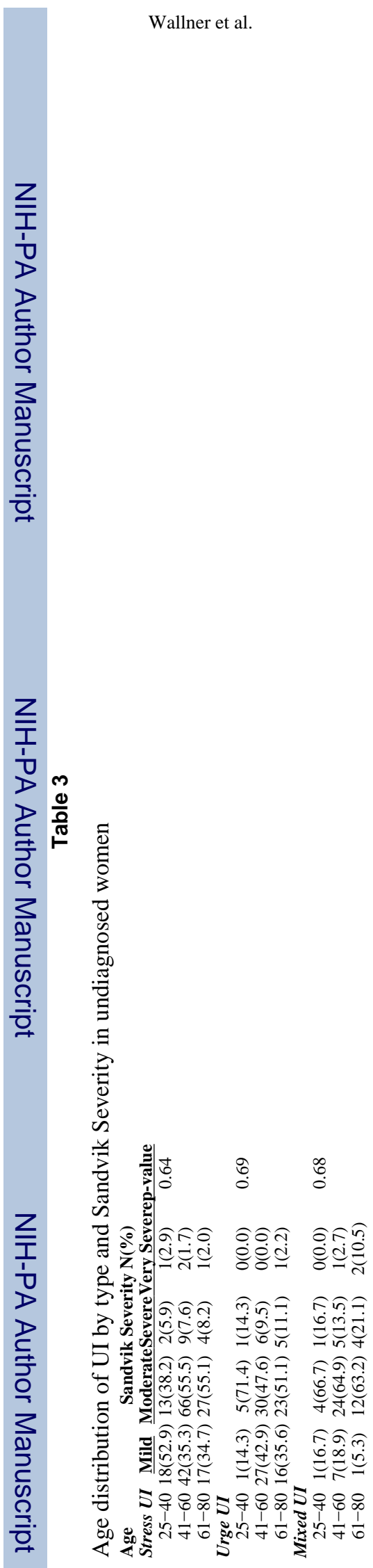

Am J Med. Author manuscript; available in PMC 2010 November 1. 


\section{Table 4}

Characteristics of women who underwent chart review by physician recognized incontinence status $(n=234)$

\begin{tabular}{lc} 
Characteristics & $\mathbf{N}(\%)$ \\
Demographics & \\
\hline Age $($ mean, median) & $54.8(55)$ \\
$25-34$ & $9(3.9)$ \\
$35-44$ & $40(17.1)$ \\
$45-54$ & $69(29.5)$ \\
$55-64$ & $63(26.9)$ \\
$65-74$ & $36(15.3)$ \\
$75+$ & $17(7.3)$ \\
Race & \\
White & $221(94.4)$ \\
Other & $13(5.6)$ \\
Education & \\
< 11 years & $5(2.1)$ \\
High school graduate or 12 yrs & $431(13.2)$ \\
Post-high school training & $30(12.8)$ \\
Some college & $82(35.0)$ \\
College Graduate & $32(13.7)$ \\
Post-graduate & $46(19.7)$ \\
Urinary Incontinence type & \\
\hline Stress & $102(43)$ \\
Urge & $75(32)$ \\
Mixed & $57(24)$ \\
Clinical characteristics & mean(median) \\
\# office contacts & $5.1(4)$ \\
\# primary care contacts & $2.4(2)$ \\
\# health maintenance exams & $1.2(1)$ \\
\# OB/Gyn contacts & $0.5(0)$ \\
\# Specialist visits & $2.7(2)$ \\
\# phone contacts & $2.9(2)$ \\
\end{tabular}

